\title{
Effects of Developmental Stages, Light, and an Auxin Polar Transport Inhibitor on the Skin and Flesh Pigmentation of Red-fleshed Peach Fruit
}

\author{
Inna Martha Rumainum ${ }^{1,2}$, Kanjana Worarad ${ }^{1,2}$, Yoshikazu Yamaki ${ }^{2}$ and Kenji Yamane $^{2 *}$ \\ ${ }^{1}$ United Graduate School of Agricultural Science, Tokyo University of Agriculture and Technology, Fuchu 183-8509, Japan \\ ${ }^{2}$ Faculty of Agriculture, Utsunomiya University, Utsunomiya 321-8505, Japan
}

\begin{abstract}
A red-fleshed peach (Prunus persica L. Batsch 'Tenshin Suimitsuto'; 'Tianjinshuimi' in Chinese) was used to study the mechanisms of skin and flesh pigmentation. Anthocyanin accumulation was detected at the preendocarp-hardening and maturation stages in skin, while it appeared from maturation stage in flesh. The flesh at harvest stage contained approximately $1.1 \mathrm{mg} \cdot \mathrm{g}^{-1} \mathrm{FW}$ of anthocyanin. In contrast, flavonoid and phenolic compounds were found in all stages. The final phenolics concentration was $1.6 \mathrm{mg} \cdot \mathrm{g}^{-1} \mathrm{FW}$. To study the effects of light, fruits were on-tree bagged in double-layered paper bags. The total anthocyanin content in the skin was significantly lowered by bagging, but not in the flesh. This suggested that flesh tissue pigmentation was less sensitive to light intensity than that of skin tissue, and thus, anthocyanin accumulation in flesh occurred even under low light conditions. Dark treatments, such as triple-layered paper bagging, significantly reduced anthocyanin and phenolic concentrations in the skin and flesh. A combined treatment of darkness and an auxin polar transport inhibitor, 2,3,5-triiodobenzoic acid (TIBA), had no effect on anthocyanin concentration in skin and flesh. However, total flavonoids in the skin was increased by TIBA treatments under darkness. Factors affecting anthocyanin accumulation in the flesh tissue are discussed.
\end{abstract}

Key Words: anthocyanin, bagging, flavonoid, phenolics, TIBA.

\section{Introduction}

Peach (Prunus persica L. Batsch) is an important Rosacea species that is grown worldwide. The fruit is favored for its sweet taste, juice and scent, and is generally consumed as table or canned fruit.

Skin color is an essential factor in the evaluation of fruit quality. Fruit skin turns red due to anthocyanin accumulation during fruit maturation. This accumulation is affected by several factors, such as light conditions (Arakawa, 1988; Awad et al., 2001; Matsuyama et al., 2014), temperature (Faragher, 1983; Lin-Wang et al., 2011; Mori et al., 2005), and fruit developmental stages (Jiao et al., 2014; Tsuda et al., 2004). In peach fruits, bagging treatments decrease skin coloration (Jia et al., 2005), demonstrating that light is an important factor in the anthocyanin accumulation in the fruit's skin. In apple, fruits grown under sufficient light accumulated greater amounts of anthocyanin, and showed better pigmentation compared with those within bags (Chen

Received; May 18, 2015. Accepted; October 6, 2015.

First Published Online in J-STAGE on November 21, 2015.

* Corresponding author (E-mail: yamane@cc.utsunomiya-u.ac.jp). et al., 2012; Wang et al., 2000). In grape berries, leafremoval treatments increased the fruit clusters' exposure to light, thereby enhancing the synthesis of delphinidin-based anthocyanin (Matsuyama et al., 2014).

Recently, polyphenols, including anthocyanins, have been considered as functional components of food (Celik et al., 2008; Wang and Lin, 2000). Although white-fleshed peach contains various nutritional compounds that are important to the human body (Rupasinghe and Clegg, 2007), it has a lower total antioxidant capacity than other fruits, such as strawberry, apple, and orange (Cantin et al., 2009). On the other hand, it was reported that red-fleshed genotypes of peach, in particular, accumulated high levels of phenolic compounds, which contribute to antioxidant activity (Cevallos-Casals et al., 2006; Vizzotto et al., 2007). Therefore, breeding peach cultivars with higher anthocyanin levels in the flesh will raise its consumer appeal and value. 'Tenshin Suimitsuto' ('Tianjinshuimi' in Chinese) is a peach cultivar that has distinctive flesh color, reddish purple, and contains remarkable amount of anthocyanin compared with other cultivars (Zhang et al., 2008; Zhao et al., 2013). This cultivar was intro- 
duced to Japan from China during the Meiji era; however, its cultivation is rare in Japan.

A "reddish-pulp" physiological disorder in which the flesh of mature fruits undergoes a pink to red discoloration has been observed in the white-fleshed Japanese cultivar 'Shimizu Hakuto' (Takata et al., 2005). Fruits with the "reddish-pulp" had high concentrations of anthocyanin and phenolic compounds in their flesh (Takata et al., 2005). The mechanism behind this disorder still remains unclear (Takata et al., 2006).

Auxin plays important roles in peach fruit ripening, and the auxin concentration in mesocarps increases prior to peach fruit maturation (Miller et al., 1987). It also regulates ethylene production and vice versa (Trainotti et al., 2007). Previous studies have verified the interaction between auxin and ethylene in several higher plants, including rice (Chae et al., 2000) and Arabidopsis (Rahman et al., 2002). In peach fruits, synthetic auxin, 1-naphthalene acetic acid (NAA), induced anthocyanin accumulation in mesocarp discs (Ohmiya, 2000).

The aim of this study was to investigate factors involved in the accumulation of anthocyanin, particularly in the flesh of 'Tenshin Suimitsuto'. The contents of total phenolics, flavonoids and anthocyanins in skin and flesh were determined at different developmental stages to reveal the relationship between fruit development and phenolic compound accumulation. Fruits were bagged in different paper bags to examine the effects of light on the pigmentation of skin and flesh. Additionally, an auxin polar transport inhibitor, 2,3,5triiodobenzoic acid (TIBA), was applied to the fruits during bagging to determine the influences of auxin on fruit pigmentation and phenolic compound accumulation.

\section{Materials and Methods}

\section{Plant material}

Fruits from three 15-year-old red-fleshed 'Tenshin Suimitsuto' peach trees [Prunus persica (L.) Batsch] grown in the field of Utsunomiya University were harvested during the 2013 and 2014 growing season. Fruits were randomly collected from each tree, and used for analysis.

\section{Effects of fruit developmental stages on fruit pigmenta- tion (2014)}

Fruits were collected five times, coinciding with five different developmental stages: May 24 [49 days after full bloom (DAFB); pre-endocarp-hardening stage], June 11 (67 DAFB; early endocarp-hardening stage), June 26 (82 DAFB; late endocarp-hardening stage), July 10 (96 DAFB; early maturation stage), and July 24 (110 DAFB; late maturation stage). Three fruits were used in each stage. Sample tissues were cut from two equatorial parts of fruit. Thin layer of skin was separated from flesh tissue $(<1 \mathrm{~cm}$ in depth from fruit surface) with a knife. All samples were frozen immediately in liquid nitrogen, and stored at $-80^{\circ} \mathrm{C}$ for anthocyanins, flavonoids and phenolics assays.

The extraction of anthocyanins was conducted following the method described by Ohmiya (2000) with slight modifications. Briefly, $1 \mathrm{~g}$ of skin or flesh was ground with a mortar and pestle, immersed in methanol containing $1 \%(\mathrm{v} / \mathrm{v}) \mathrm{HCl}$ at $4^{\circ} \mathrm{C}$ for $12 \mathrm{~h}$, and then centrifuged at $6000 \times \mathrm{g}$ before being filtered through filter paper (No. 2; Whatman, Buckinghamshire, UK). The total anthocyanin content in the supernatant was determined by measuring the absorbance at $528 \mathrm{~nm}$, and was expressed as $\mu \mathrm{g}$ or $\mathrm{mg}$ of cyanidin 3-glucoside per $\mathrm{g}$ FW.

The total flavonoid content was measured following the procedure described by Cantin et al. (2009). Briefly, $0.3 \mathrm{~mL}$ of $5 \%$ sodium nitrite was added to $1 \mathrm{~mL}$ of methanolic extract diluted with water $(1: 2)$, and vortexed. After $5 \mathrm{~min}, 0.3 \mathrm{~mL}$ of $10 \%$ aluminum chloride was added, and mixed for $1 \mathrm{~min}$. Then, $2 \mathrm{~mL}$ of $1 \mathrm{~N}$ sodium hydroxide was added and mixed by vortexing for $30 \mathrm{~s}$ before the measurement was taken. The absorbance at $510 \mathrm{~nm}$ was recorded, and the total flavonoid concentration was expressed as $\mathrm{mg}$ of catechin equivalents per g FW.

The total phenolics concentration was measured using the Folin-Ciocalteu method as described by Cantin et al. (2009). A drop of $0.5 \mathrm{~mL}$ Folin-Ciocalteu reagent was added to $0.5 \mathrm{~mL}$ of methanol extracts diluted in distilled water. After $3 \mathrm{~min}, 1 \mathrm{~mL}$ of $1 \mathrm{~N}$ sodium carbonate was added. The solution was mixed for $15 \mathrm{~s}$, and allowed to stand for $1 \mathrm{~h}$ at $25^{\circ} \mathrm{C}$. The absorbance was measured at $725 \mathrm{~nm}$ using a spectrophotometer. The total phenolics concentration was expressed as $\mathrm{mg}$ of gallic acid equivalents per $\mathrm{g} \mathrm{FW}$.

Effects of the double-layered paper bag treatment on the accumulation of anthocyanin (2013)

On May 24 (40 DAFB), fruits were on-tree bagged in a double-layered paper bag $(18.0 \times 16.7 \mathrm{~cm}, 1-\mathrm{S}$ Tokudai BH72A, outer and inner layers are printed and red paper, respectively; Kobayashi Seitai Corp., Iida, Japan $)$ and a white paper bag $(28.9 \times 23 \mathrm{~cm}$, grape19 BA16A; Kobayashi Seitai Corp.). The white paper bag was used as the control. The light transparency of each bag was determined using a PAR photometer (ML-20P, EKO Instruments, Tokyo, Japan), and the average percentage of shading was calculated. The shading rates were $95 \%$ for the double-layered bag, and $26 \%$ for the white bag. Fruits were collected on July 28 (105 DAFB), and 10 fruits were measured from each treatment. Samples for the anthocyanin assay were frozen immediately in liquid nitrogen and stored at $-20^{\circ} \mathrm{C}$. Skin color was measured using a colorimeter (NR-3000; Nippon Denshoku Industries, Tokyo, Japan) three times, and expressed as lightness $\left(\mathrm{L}^{*}\right)$, chroma $\left(\mathrm{C}^{*}\right)$ and hue angle $\left(\mathrm{h}^{\circ}\right)$. Total soluble solids (TSS) in 
juice was measured using a refractometer (PR-1; Atago, Tokyo, Japan) and expressed as ${ }^{\circ}$ Brix. Titratable acidity (TA) was determined by titrating with $0.1 \mathrm{~N} \mathrm{NaOH}$, and expressed as the percentage of malic acid. Total anthocyanin concentration was measured as described above.

\section{Effects of darkness within triple-layered paper bags and} TIBA treatments on the accumulation of anthocyanin (2014)

At 49 DAFB, fruits were placed in triple-layered bags used for apples $(19.5 \times 16.1 \mathrm{~cm}$; Sun color: outer, middle, and inner layers are blue, black, and red, respectively; Murakami Seitai Corp., Hirosaki, Japan), and a white paper bag (described above) was used as the control. The shading rate of the triple-layered bag was $100 \%$, thus fruits in the bag matured in darkness (i.e., Dark treatment). At 91 DAFB, the triple-layered bags were removed, and a $25 \mathrm{~mL}$ solution of $100 \mu \mathrm{M}$ TIBA was hand-sprayed over half of the dark treatment fruits, and then fruits were re-covered with new triplelayered bags. On July 25 (111 DAFB), fruits were harvested, and 10 fruits were used as control. Owing to brown rot, seven fruits were used for the dark treatment. Skin color, TSS, TA, total anthocyanin, total flavonoid, and total phenolics were measured as described above.

Ethylene production was measured $2 \mathrm{~h}$ after harvest. Individual fruits of each treatment were put inside $1 \mathrm{~L}$ plastic containers capped with lids, which were fitted with silicone rubber outlets, for $1 \mathrm{~h}$ at $25^{\circ} \mathrm{C}$. Then, $1 \mathrm{~mL}$ gas samples were taken from the headspace to determine ethylene concentrations by gas chromatography with a flame ionization detector (GC-15 A; Shimadzu, Kyoto, Japan) and an activated alumina column $(2.0 \mathrm{~m}$ $\times 3.0 \mathrm{~mm}$ I.D.; Shinwa Chemical Industries Ltd., Kyoto, Japan).

\section{Statistical analysis}

All data were subjected to an analysis of variance, and significant differences of the means were evaluated using Tukey-Kramer's multiple comparison tests or Student's $t$-test.

\section{Results}

Effects of fruit developmental stages on fruit pigmentation

In 'Tenshin Suimitsuto' peach, fruit weight was almost constant during the pre-endocarp-hardening stage (May 24) and then increased rapidly during the endocarp-hardening stage (June 11 and 26) until the early maturation stage (July 10). Its growth gradually stopped at the late maturation stage (July 24) as shown in Figure 1A.

A small amount of anthocyanin was detected in the skin at the pre-endocarp-hardening stage, and then disappeared, to be detected again at the late maturation stage (Fig. 1B). In the flesh, however, it did not accumulate until the early maturation stage, then increased
A
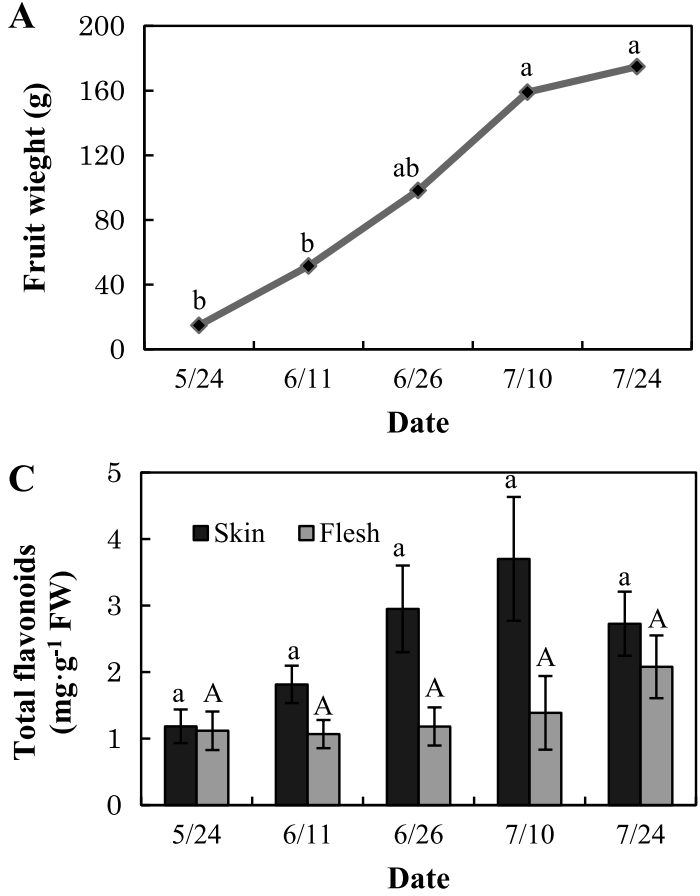

B
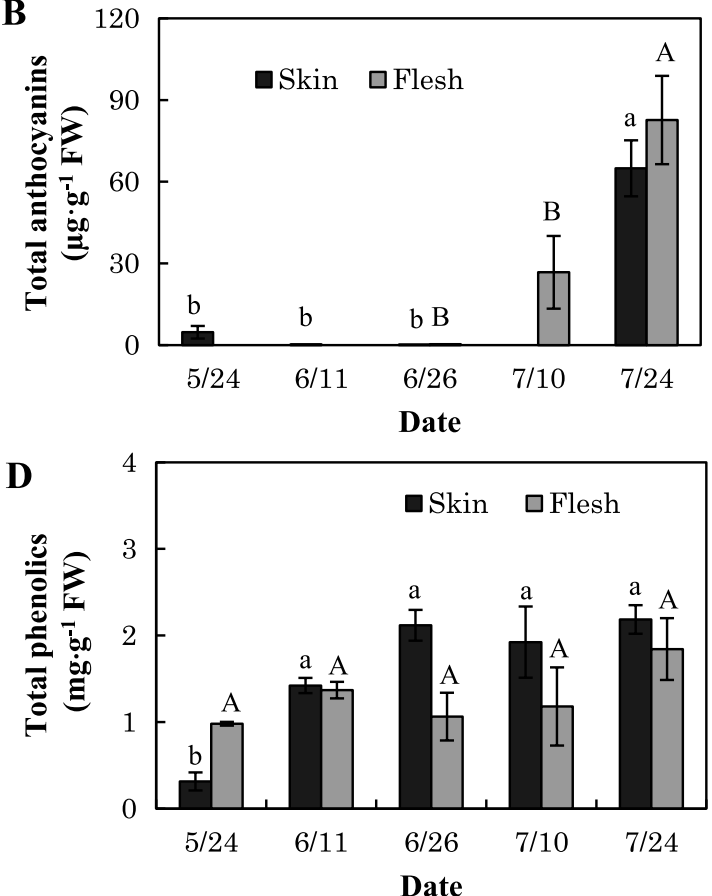

Fig. 1. Changes in fruit weights and concentrations of anthocyanins, flavonoids, and phenolics in 'Tenshin Suimitsuto' peach fruits. A: Fruit weight, B: Anthocyanin, C: Flavonoid, D: Phenolics. A: Different letters indicate significant differences among sampling date at $P<0.05$ by Tukey-Kramer's multiple comparison test. B-D: Different letters indicate significant differences among sampling date in skin (small letter) or flesh (capital letter). Vertical bars indicate $\pm \mathrm{SE}$. 
A

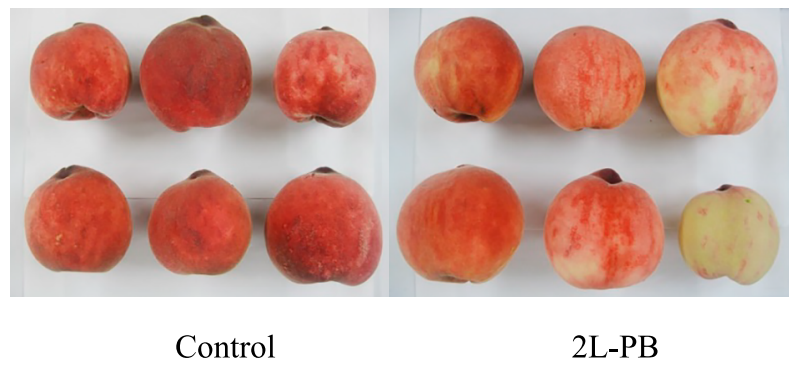

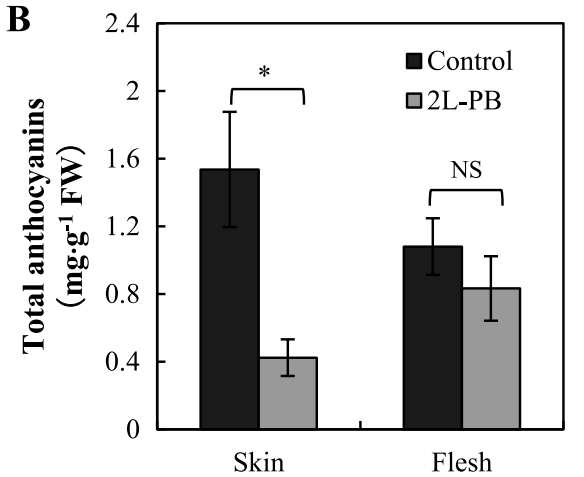

Fig. 2. Effects of double-layered paper bags (2L-PB) on pigmentation and anthocyanin accumulation in 'Tenshin Suimitsuto' peach fruits. A: Fruit skin pigmentation, B: Anthocyanin content. NS, *: Not significant, significantly different at $P<0.05$ by Student's $t$-test. Vertical bars indicate $\pm \mathrm{SE}$.

Table 1. Effects of the double-layered paper bag on skin pigmentation and fruit quality of 'Tenshin Suimitsuto' fruits.

\begin{tabular}{cccccc}
\hline \hline Treatments & L* & C & $\mathrm{h}^{*}$ & TSS ( ${ }^{\circ}$ Brix $)$ & TA (\%) \\
\hline Control & $40.4 \pm 1.3^{\mathrm{y}}$ & $71.3 \pm 2.5$ & $11.7 \pm 1.0$ & $9.0 \pm 0.3$ & $0.5 \pm 0.1$ \\
$2 \mathrm{~L}-\mathrm{PB}^{\mathrm{z}}$ & $49.8 \pm 2.4$ & $62.7 \pm 4.2$ & $21.6 \pm 3.7$ & $8.4 \pm 0.4$ & $0.4 \pm 0.1$ \\
\hline & $* * x$ & NS & $*$ & NS & NS \\
\hline
\end{tabular}

${ }^{\mathrm{z}}$ Bagging with double-layered paper bag.

y Data are the means \pm SE.

${ }^{x} \mathrm{NS}, * * *$ : not significant, significantly different at $P<0.05$ or $P<0.01$ by Student's $t$-test, respectively.

markedly with fruit ripening (Fig. 1B).

Flavonoids and phenolics were detected at all developmental stages in both skin and flesh (Fig. 1C, D). Phenolics content in skin increased until the endocarphardening stage.

Effects of the double-layered paper bag on the color and accumulation of anthocyanins

Fruits placed in double-layered bags (95\% shading) had weaker skin pigmentation (Fig. 2A), and significantly $(P<0.05)$ higher $\mathrm{L}^{*}$ and $\mathrm{h}^{\circ}$ values compared with controls, indicating that the final skin color remained yellow (Table 1). The anthocyanin concentrations in the control fruits' skin and flesh were 1.5 and $1.1 \mathrm{mg} \cdot \mathrm{g}^{-1} \mathrm{FW}$, respectively (Fig. 2B). The shading treatment significantly decreased the anthocyanin accumulation in the skin, while it had no influence on that in the flesh (Fig. 2B). There was no significant difference by double-layered bagging treatment in regard to TSS and TA (Table 1).

\section{Effects of darkness within triple-layered paper bags and} TIBA treatments on the accumulation of anthocyanins

Dark treatment suppressed skin pigmentation (Fig. 3). For skin color, darkness and darkness combined with TIBA (dark+TIBA) significantly increased $\mathrm{L}^{*}$ and $\mathrm{h}^{\circ}$ values, while decreased $\mathrm{C}^{*}$ (Table 2). Ethylene production was not affected by dark or dark+TIBA treatments (Table 2). TSS was not significantly influenced by dark or dark+TIBA (Table 2). The dark+TIBA

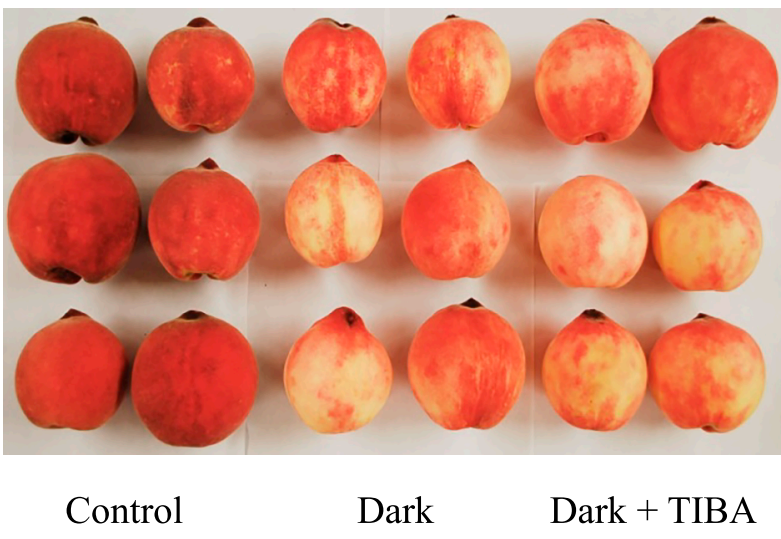

Fig. 3. Effect of darkness and TIBA treatments on skin pigmentation. Dark: Triple-layered paper bags.

treatment had the highest TA, followed by darkness alone and then the control (Table 2).

Total anthocyanins level in skin was significantly $(P$ $<0.05)$ lower in darkness and dark+TIBA treatments by 8- and 7-fold, respectively, compared with the control (Fig. 4A), while in flesh it was 3-fold lower in darkness and dark+TIBA treatments.

Flavonoid content in skin and flesh were different. In skin, fruits treated with dark+TIBA showed high flavonoid contents (Fig. 4B). However, the total flavonoids level in flesh was significantly lowered by darkness and dark+TIBA (Fig. 4B). Dark, and dark combined with 
Table 2. Effects of darkness and TIBA treatments on the skin pigmentation and fruit quality of 'Tenshin Suimitsuto' fruits.

\begin{tabular}{lcccccc}
\hline \hline Treatments & $\mathrm{L}^{*}$ & $\mathrm{C}^{*}$ & $\mathrm{~h}^{\circ}$ & Ethylene $\left(\mu \mathrm{L} \cdot \mathrm{kg}^{-1} \cdot \mathrm{h}^{-1}\right)$ & TSS $\left({ }^{\circ}\right.$ Brix $)$ & TA $(\%)$ \\
\hline Control & $43.0 \pm 1.3 \mathrm{~b}^{\mathrm{x}}$ & $68.7 \pm 2.6 \mathrm{a}$ & $13.3 \pm 1.1 \mathrm{~b}$ & $2.4 \pm 0.3 \mathrm{a}$ & $7.6 \pm 0.3 \mathrm{a}$ & $0.5 \pm 0.0 \mathrm{c}$ \\
Dark $^{z}$ & $60.0 \pm 2.9 \mathrm{a}$ & $51.4 \pm 4.6 \mathrm{~b}$ & $28.3 \pm 4.2 \mathrm{a}$ & $1.3 \pm 0.5 \mathrm{a}$ & $7.6 \pm 0.5 \mathrm{a}$ & $0.7 \pm 0.1 \mathrm{~b}$ \\
Dark+TIBA $^{y}$ & $62.3 \pm 2.6 \mathrm{a}$ & $49.5 \pm 4.6 \mathrm{~b}$ & $34.8 \pm 4.4 \mathrm{a}$ & $1.7 \pm 0.4 \mathrm{a}$ & $8.5 \pm 0.3 \mathrm{a}$ & $0.9 \pm 0.1 \mathrm{a}$ \\
\hline
\end{tabular}

${ }^{\mathrm{z}}$ Bagging with triple-layered paper bags.

y A solution of $25 \mathrm{~mL}$ of $100 \mu \mathrm{M}$ 2,3,5-triiodobenzoic acid (TIBA) was sprayed.

x Values within a column followed by the same letter are not significantly different at $P<0.05$ by Tukey-Kramer's multiple comparison test. Data are the means \pm SE.

A
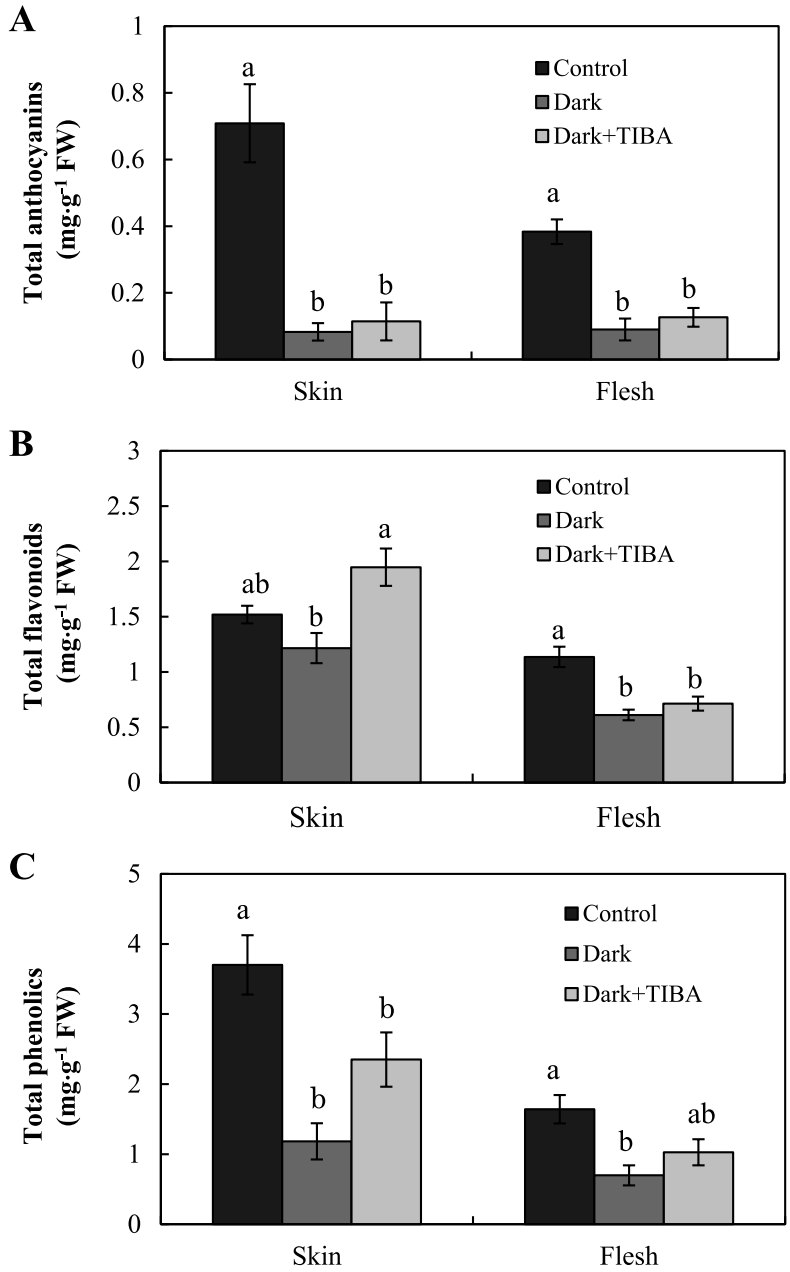

Fig. 4. Effects of darkness and TIBA treatments on the accumulation of anthocyanins (A), flavonoids (B), and phenolics (C) in the skin and flesh of peach fruits. Different letters indicate significant differences among treatments within skin or flesh at $P$ $<0.05$ by Tukey-Kramer's multiple comparison tests. Vertical bars indicate \pm SE.

TIBA treatments reduced phenolic level in both skin and flesh (Fig. 4C).

\section{Discussion}

Red-fleshed 'Tenshin Suimitsuto' accumulated anthocyanin in skin and flesh during fruit ripening (Fig. 1B). Zhang et al. (2008) also reported that anthocyanin level of 'Tenshin Suimitsuto' rapidly increased between 86 and 96 DAFB. It is noteworthy that anthocyanin was accumulated in the flesh prior to skin at the early maturation stage. This color development pattern has also been reported in red-fleshed grape berries in which the flesh starts to accumulate anthocyanins earlier than the skin (Castellarin et al., 2011). At harvest stage, the anthocyanin content in the fruit's skin and flesh of 'Tenshin Suimitsuto' was 1.5 and $1.1 \mathrm{mg} \cdot \mathrm{g}^{-1}$ $\mathrm{FW}$, respectively.

Generally, in fruit, it has been suggested that flavonoid compounds, such as flavonols and proanthocyanidins, are synthesized from early stages, acting as astringent and defense compounds for protection against predators and pathogens (Harborne, 1997), and then decrease during ripening as anthocyanin and other ripening-related compounds are synthesized ( $\mathrm{Li}$ et al., 2002). However, 'Tenshin Suimitsuto' maintained flavonoid and phenolic concentrations even as the fruit ripened (Fig. 1C, D). The TSS was relatively low, 8 $9^{\circ}$ Brix, and the TA was high, $0.5 \%$, in 'Tenshin Suimitsuto' (Tables 1 and 2). Thus, sweeter and less sour cultivars, like 'Shanhai Suimitsuto', have been used for peach breeding in Japan (Yamamoto et al., 2003). However, since consumers are becoming more health-oriented as the population ages, higher contents of antioxidants, such as phenolics and anthocyanin, may be considered as a desirable factor in peach fruits.

Bagging treatments reduced the anthocyanin accumulation in several fruits, including peach (Jia et al., 2005). The present study showed that shading treatment reduced anthocyanin accumulation in the flesh but its level of reduction was less than that in the skin (Fig. 2B). Takata et al. (2006) reported that in "reddishpulp" fruits bagging treatments using different colored bags did not suppress the physiological disorder. These results indicated that flesh tissue was less sensitive to light intensity, and that the anthocyanin accumulation in flesh occurred even under low light conditions.

The application of NAA resulted in the accumulation of anthocyanin in peach mesocarp tissue (Ohmiya, 2000). Many studies have reported the regulation of flavonoids by auxin transport, and vice versa, in response to gravity on plant roots (Brown et al., 2001; Buer and Muday, 2004; Santelia et al., 2008). We assumed that auxin was involved in the anthocyanin synthesis, thus fruits were treated with darkness combined with an 
auxin polar transport inhibitor, TIBA. However, contrary to our expectations, no marked suppression in anthocyanin accumulation in either of skin or flesh was observed. Instead, the concentrations of flavonoid increased in the skin under darkness (Fig. 4). Sprayed TIBA might act in the skin tissue, inhibiting the transportation of auxin from the skin to other fruit parts, and thereby increasing the skin flavonoid concentration. In a preliminary experiment, however, anthocyanin accumulation in mesocarp discs of 'Tenshin Suimitsuto' on an agarose medium was inhibited by TIBA treatments (data not shown), suggesting that TIBA might inactivate anthocyanin synthesis in detached mesocarp tissues with limited auxin level. Further studies, including auxin treatments of the fruits, will be needed to verify the effects of auxin on flesh pigmentation.

In conclusion, the accumulation of anthocyanin and phenolic compounds in flesh of 'Tenshin Suimitsuto' appeared to be regulated by endogenous factors, such as fruit development, and exogenous factors, such as light.

\section{Literature Cited}

Arakawa, O. 1988. Photoregulation of anthocyanin synthesis in apple fruit under UV-B and red light. Plant Cell Physiol. 29: $1385-1389$

Awad, M. A., P. S. Wagenmakers and A. de Jager. 2001. Effects of light on flavonoid and chlorogenic acid levels in the skin of 'Jonagold' apples. Sci. Hortic. 88: 289-298.

Brown, D. E., A. M. Rashotte, A. S. Murphy, J. Normanly, B. W. Tague, W. A. Peer, L. Taiz and G. K. Muday. 2001. Flavonoids act as negative regulators of auxin transport in vivo in Arabidopsis. Plant Physiol. 126: 524-535.

Buer, C. S. and G. K. Muday. 2004. The transparent testa 4 mutation prevents flavonoid synthesis and alters auxin transport and the response of Arabidopsis roots to gravity and light. Plant Cell. 16: 1191-1205.

Cantin, C. M., M. A. Moreno and Y. Gogorcena. 2009. Evaluation of the antioxidant capacity, phenolic compounds, and vitamin $\mathrm{C}$ content of different peach and nectarine (Prunus persica L. Batsch) breeding progenies. J. Agric. Food Chem. 57: 4586-4592.

Castellarin, S. D., G. A. Gambetta, H. Wada, K. A. Shackel and M. A. Matthews. 2011. Fruit ripening in Vitis vinifera: spatiotemporal relationships among turgor, sugar accumulation, and anthocyanin biosynthesis. J. Exp. Bot. 62: 4345-4354.

Celik, H., M. Ozgen, S. Serce and C. Kaya. 2008. Phytochemical accumulation and antioxidant capacity at four maturity stages of cranberry fruit. Sci. Hortic. 117: 345-348.

Cevallos-Casals, B. A., D. Byrne, W. R. Okie and L. CisnerosZevallos. 2006. Selecting new peach and plum genotypes rich in phenolic compounds and enhanced functional properties. Food Chem. 96: 273-280.

Chae, H. S., Y. G. Cho, M. Y. Park, M. C. Lee, M. Y. Eun, B. G. Kang and W. T. Kim. 2000. Hormonal cross-talk between auxin and ethylene differentially regulates the expression of two members of the 1-aminocyclopropane-1-carboxylate oxidase gene family in rice (Oryza sativa L.). Plant Cell Physiol. 41: 354-362.

Chen, C., D. Zhang, Y. Wang, P. Li and F. Ma. 2012. Effects of fruit bagging on the contents of phenolic compounds in the peel and flesh of 'Golden Delicious', 'Red Delicious', and 'Royal Gala' apples. Sci. Hortic. 142: 68-73.
Faragher, J. D. 1983. Temperature regulation of anthocyanin accumulation in apple skin. J. Exp. Bot. 34: 1291-1298.

Harborne, J. 1997. Phytochemistry of fruits and vegetables: an ecological overview. p. 335-367. In: F. A. Tomas-Barberan and R. J. Robins (eds.). Phytochemistry of fruits and vegetables. Oxford University Press Inc., New York.

Jia, H.-J., A. Araki and G. Okamoto. 2005. Influence of fruit bagging on aroma volatiles and skin coloration of 'Hakuho' peach (Prunus persica Batsch). Postharvest Biol. Technol. 35: 61-68.

Jiao, Y., R. Ma, Z. Shen, J. Yan and M. Yu. 2014. Gene regulation of anthocyanin biosynthesis in two blood-flesh peach (Prunus persica (L.) Batsch) cultivars during fruit development. Biomed. Biotechnol. 15: 809-819.

Li, Z., S. Sugaya, H. Gemma and S. Iwahori. 2002. Flavonoid biosynthesis and accumulation and related enzyme activities in the skin of 'Fuji' and 'Oorin' apples during their development. J. Japan. Soc. Hort. Sci. 71: 317-321.

Lin-Wang, K., D. Micheletti, J. Palmer, R. Volz, L. Lozano, R. Espley, R. P. Hellens, D. Chagne, D. D. Rowan, M. Troggio, I. Iglesias and A. C. Allan. 2011. High temperature reduces apple fruit colour via modulation of the anthocyanin regulatory complex. Plant Cell Environ. 34: 1176-1190.

Matsuyama, S., F. Tanzawa, H. Kobayashi, S. Suzuki, R. Takata and H. Saito. 2014. Leaf removal accelerated accumulation of delphinidin-based anthocyanins in 'Muscat Bailey A' [Vitis $\times$ labruscana (Bailey) and Vitis vinifera (Muscat Hamburg)] grape skin. J. Japan. Soc. Hort. Sci. 83: 17-22.

Miller, A. N., C. S. Walsh and J. D. Cohen. 1987. Measurement of indole-3-acetic acid in peach fruits (Prunus persica L. Batsch cv. Redhaven) during development. Plant Physiol. 141: 1617-1629.

Mori, K., S. Sugaya and H. Gemma. 2005. Decreased anthocyanin biosynthesis in grape berries grown under elevated night temperature condition. Sci. Hortic. 105: 319-330.

Ohmiya, A. 2000. Effects of auxin on growth and ripening of mesocarp discs of peach fruit. Sci. Hortic. 84: 309-319.

Rahman, A., S. Hosokawa, Y. Oono, T. Amakawa, N. Goto and S. Tsurumi. 2002. Auxin and ethylene response interactions during Arabidopsis root hair development dissected by auxin influx modulators. Plant Physiol. 130: 1908-1917.

Rupasinghe, H. P. and S. Clegg. 2007. Total antioxidant capacity, total phenolic content, mineral elements, and histamine concentrations in wines of different fruit sources. J. Food Comp. Anal. 20: 133-137.

Santelia, D., S. Henrichs, V. Vincenzetti, M. Sauer, L. Bigler, M. Klein, A. Bailly, Y. Lee, J. Friml, M. Geisler and E. Martinoia. 2008. Flavonoids redirect PIN-mediated polar auxin fluxes during root gravitropic responses. J. Biol. Chem. 283: 31218-31226.

Takata, D., F. Fukuda and N. Kubota. 2006. Effects of fruit position in canopy, harvest date and bagging on occurrence of reddish-pulp fruit in peach. Hort. Res. (Japan) 5: 33-37 (In Japanese with English abstract).

Takata, D., K. Tagami, F. Fukuda and N. Kubota. 2005. Characterization of "reddish-pulp", a physiological disorder of peach fruit. J. Japan. Soc. Hort. Sci. 74: 407-413 (In Japanese with English abstract).

Trainotti, L., A. Tadiello and G. Casadoro. 2007. The involvement of auxin in the ripening of climacteric fruits comes of age: the hormone plays a role of its own and has an intense interplay with ethylene in ripening peaches. J. Exp. Bot. 58: 3299-3308.

Tsuda, T., M. Yamaguchi, C. Honda and T. Moriguchi. 2004. Expression of anthocyanin biosynthesis genes in the skin of 
peach and nectarine fruit. J. Amer. Soc. Hort. Sci. 129: 857862.

Vizzotto, M., L. Cisneros-Zevallos, D. H. Byrne, D. W. Ramming and W. R. Okie. 2007. Large variation found in the phytochemical and antioxidant activity of peach and plum germplasm. J. Amer. Soc. Hort. Sci. 132: 334-340.

Wang, S. Y. and H.-S. Lin. 2000. Antioxidant activity in fruits and leaves of blackberry, raspberry, and strawberry varies with cultivar and developmental stage. J. Agric. Food Chem. 48: 140-146.

Wang, H., O. Arakawa and Y. Motomura. 2000. Influence of maturity and bagging on the relationship between anthocyanin accumulation and phenylalanine ammonia-lyase (PAL) activity in 'Jonathan' apples. Postharvest Biol. Technol. 19:
$123-128$.

Yamamoto, T., K. Mochida and T. Hayashi. 2003. Shanhai Suimitsuto, one for the origin of Japanese peach cultivars. J. Japan. Soc. Hort. Sci. 72: 116-121.

Zhang, Q., J. Li, L. Wang, G. Zhu, W. Fang, K. Cao, C. Chen and Y. Feng. 2008. Study on the changes of contents of pigments, sugar and acid of blood-flesh peach cultivar during fruit development. J. Fruit Sci. 25: 312-315 (In Chinese with English abstract)

Zhao, Y., L. Wang, K. Cao, G. Zhu, W. Fang, C. Chen and F. Peng. 2013. Genetic diversity of anthocyanin in peach fruit and the evaluating criterion of red-fleshed peach. J. Plant Gen. Res. 14: 167-173 (In Chinese with English abstract). 